\title{
Business Intelligence and Big Data Analytics for Higher Education: Cases from UK Higher Education Institutions
}

\author{
Vincent Koon Ong *
}

\begin{abstract}
With the rise of big data, its impact has becoming apparent even in the Higher Education sector. The strategic use and applications of big data in higher education would lead to higher educational quality and better student and staff experience. Using the output from UK JISC's Business Intelligence projects, this paper reviews and outlines eleven cases of big data analytics in the UK Higher Education institutions, followed by presenting one of the projects to demonstrate the application of big data analytics on student engagement. This leads to further research implications for future big data research in Higher Education.
\end{abstract}

Keywords: big data analytics, business intelligence, student engagement, visualization

\section{Introduction}

With the ever-increasing creation of massive amounts of structured and unstructured data in a more and more distributed business environment, organizations are forced to seek new technical solutions and managerial approaches in dealing with data. As a result, the concepts and applications of big data have taken the business world by storm. Organizations that employ big data have begun to reap tangible and intangible benefits from it, for examples, the insights drawn from big data give the organization the ability to offer each customer an individual experience and with that experience, the organization is able to improve their customer relationship management. Chen et al. [1] identify five areas as "big impact" areas of big data research: (1) e-commerce and market intelligence, (2) e-government and politics, (3) science and technology, (4) smart health and well being, and (5) security and public safety. Higher education is another potential impact area for big data research. According to Universities UK's latest UK-wide study on the impact of the higher education sector on the UK economy in 2011-12, universities now generate $£ 73$ billion in output - up (24\%) from $£ 59$ billion when the last study was published in 2009 [2]. This puts higher education ahead of many other UK sectors, including advertising and market research, legal services, computer manufacturing, basic pharmaceuticals, and air transport. Universities also generate more GDP per unit of expenditure than many other sectors including health, public administration, and construction.

\footnotetext{
* Faculty of Business and Management, Regent's University London, London, UK
} 
Higher education sector relies heavily on student data for making critical and strategic decisions. Colleges and universities have been collecting and tracking more student data than ever before, from student admission to student departure, even after departure, such as application data, course registration data, attendance data, online learning data, performance data, extra-curricular data, internship and employability data. The strategic use and applications of big data in higher education would lead to higher educational quality and better student and staff experience. However, big data analytics are mostly employed to satisfy credentialing or reporting requirements rather than to address strategic issues, plus much of the data collected are not fully utilized [3].

UK JISC, a registered charity that champions the use of digital technologies in UK education and research, launched the Business Intelligence (BI) Programme in between 2011 and 2012 as part of its JISC strategy 2010-12 to help institutions develop and use their corporate and business systems efficiently and effectively. The BI Programme aims to help further and higher education institutions identify their BI maturity and build appropriate BI systems or solutions which will provide senior managers with better and more timely access to accurate data resulting in improved predictions, forecasts, benchmarking and other reports in order to meet business goals. Eleven projects have been funded by UK JISC to study a wide range of issues related to data-driven decision making activities and support for senior managers in higher education institutions in the UK. The outcomes of this BI Programme have clearly shed light on big data concepts and applications in higher education sector. This paper reviews the overall findings related big data analytics from JISC's BI Projects, followed by presenting one of the projects to demonstrate the application of big data analytics on student engagement. This leads to further research implications of big data in the higher education sectors.

\section{Big Data Analytics}

Goes [4] sees opportunities for IS research in the field of big data at three levels: (1) Big data infrastructure: This focuses on the technical issues related to data creation and collection, $4 \mathrm{Vs}$ (volume, velocity, variety, veracity) of data sources, implementation and management of big data. (2) Big data analytics: This entails the data-driven process and techniques for supporting decision making through insights gained from data analysis. (3) Transformation and impact: This informs organizations or individuals about issues such as IT-business alignment, business process transformation, deployment and utilization of big data systems.

Big data analytics are grounded in data mining and statistical analysis, and are closely related to business intelligence in the context of data-driven decision making. Therefore, big data analytics would be more critical for higher education institutions. Bichsel's study shows that big data analytic is an interest or a major priority for most universities and it can significantly advance an institution in strategic areas such as resource allocation, student success, and finance [3].

Goes [4] presents a taxonomy to describe big data analytics research projects as depicted in Figure 1. This taxonomy is employed to review 11 JISC's BI Projects in the UK. In the context of higher education, decision time is critical as student data is generated from real time, such as real time online learning activities, to weekly, such as class attendance, and to yearly, such as progression statistics. Organizations are now more interested in engaging with real-time or close to real-time decisions as they give them more competitive advantage. Analytics is the use of data, statistical analysis, and explanatory and predictive models to gain insights 
and to present data through various visualization forms [3]. Visualization forms can go from simple bar charts and pie charts to more complex and interactive visualization forms, such as interactive tree map and dynamic bubble chart. The goal of visualization is that the user can easily understand and interpret huge and complex set of data. Techniques refer to the use of statistics, econometrics, linguistics or advanced computational and machine learning methods to analyze, trends or excep-

Big Data Analytics

\begin{tabular}{|c|c|c|}
\hline Decision Time & Analytics & Techniques \\
\hline Real Time (RT) & Visualization & Statistics \\
\hline Close to RT & Exploration & Econometrics \\
\hline Hourly & Explanatory & Machine Learning \\
\hline Weekly/ Monthly & Predictive & Computational \\
\hline Yearly & & Simulation \\
\hline & & Optimization \\
\hline
\end{tabular}
interpret or predict tions in data.

Figure 1: Taxonomy of Big Data Analytics (Goes, 2014)

\section{Big Data Analytics in the UK Higher Education}

This section presents and reviews the overall findings of the eleven JISC's BI Projects developed and implemented in between February 2011 to August 2012. Table 1 provides the summary of these projects. More details of these projects can be found in JISC infoNet [5].

\section{TABLE 1: SUMMARY OF JISC'S BI PROJECTS}

\begin{tabular}{|c|l|}
\hline $\begin{array}{c}\text { University \& Project } \\
\text { Subject Areas }\end{array}$ & \multicolumn{1}{c|}{ Project Summary } \\
\hline $\begin{array}{c}\text { University of Central } \\
\text { Lancashire Student } \\
\text { performance, retention } \\
\text { and progression }\end{array}$ & $\begin{array}{l}\text { The project evaluated the requirements for business intelligence on big data re- } \\
\text { lated to performance management / KPIs and developed a single BI system that } \\
\text { allows senior managers access to timely and accurate big data analytics for better } \\
\text { benchmarking and monitoring. }\end{array}$ \\
\hline $\begin{array}{c}\text { University of Bolton } \\
\text { Budget and workload } \\
\text { planning }\end{array}$ & $\begin{array}{l}\text { The project determined a means of defining, capturing and reusing big data to } \\
\text { better support operational priorities and strategic decision-making. }\end{array}$ \\
\hline $\begin{array}{c}\text { University of East London } \\
\text { performance benchmarking }\end{array}$ & $\begin{array}{l}\text { The project has enhanced three BI applications on big data related to student } \\
\text { lifecycle, benchmarking and corporate performance for supporting senior man- } \\
\text { agers' strategic planning processes. }\end{array}$ \\
\hline $\begin{array}{c}\text { University of Sheffield } \\
\text { Student admission and } \\
\text { progression }\end{array}$ & $\begin{array}{l}\text { The project developed a methodology and solution that enables users to query and } \\
\text { connects student admissions big data with external data sources, such as HESA, } \\
\text { from a single point of access. }\end{array}$ \\
\hline $\begin{array}{c}\text { University of Durham } \\
\text { Performance benchmarking }\end{array}$ & $\begin{array}{l}\text { The project gathered a set of big data from Higher Education institutions that } \\
\text { allows the current structures within national data sets to be mapped to } \\
\text { department structures within each institution. }\end{array}$ \\
\hline $\begin{array}{c}\text { University of Glasgow } \\
\text { Research interests and } \\
\text { output }\end{array}$ & $\begin{array}{l}\text { The project integrated, visualized and automated the production of big data on } \\
\text { research clusters at the University of Glasgow, thereby improving access to this } \\
\text { data in support of strategic decision making, publicity, enhancing } \\
\text { collaboration and interdisciplinary research, and research data reporting. }\end{array}$ \\
\hline
\end{tabular}




\begin{tabular}{|c|l|}
\hline $\begin{array}{c}\text { University of Manchester } \\
\text { Facilities and utilities } \\
\text { optimisation }\end{array}$ & $\begin{array}{l}\text { The project developed a BI system that supports the collection, analysis and } \\
\text { management of Estates Management Statistics (EMS) and to provide the } \\
\text { University senior managers with better data analytics and timely access to accu- } \\
\text { rate data, reports and predictive analysis in relation to environmental and sus- } \\
\text { tainability data. }\end{array}$ \\
\hline $\begin{array}{c}\text { Liverpool University } \\
\text { Performance benchmarking }\end{array}$ & $\begin{array}{l}\text { The project designed and implemented a Management Information solution to } \\
\text { convert big data into useful information for business process improvement and } \\
\text { change management. }\end{array}$ \\
\hline $\begin{array}{c}\text { Open University Student } \\
\text { engagement, retention and } \\
\text { progression }\end{array}$ & $\begin{array}{l}\text { The project developed predictive modelling techniques to identify students at risk } \\
\text { and developed a process for the automatic daily export of VLE data into the cur- } \\
\text { rent university data warehouse to link these big data sources. }\end{array}$ \\
\hline $\begin{array}{c}\text { University of } \\
\text { Bedfordshire }\end{array}$ & $\begin{array}{l}\text { The project demonstrated how the adoption of a student engagement tracking } \\
\text { system can support and enhance institutional decision making with evidence in big } \\
\text { data analytics. }\end{array}$ \\
\hline $\begin{array}{c}\text { Student engagement, } \\
\text { Hudention and progression }\end{array}$ & $\begin{array}{l}\text { The project merged big data from internal information extracted from an institu- } \\
\text { tion's publications repository with external information (academic subject defi- } \\
\text { nitions, quality of outlets and publications), for input to a visualization tool. }\end{array}$ \\
\hline
\end{tabular}

Referring to Goes' [4] taxonomy of big data analytics, most institutions do not use big data analytics on real time basis. Most institutions are using transactional and system-generated data. In some cases, data warehouses are in place as a way to integrate, organize and summarize large datasets. Reporting tends to be required on weekly and monthly basis, such as weekly student admission report, monthly report on student engagement and employability data. The historical data generation has also been challenging for institutions to identify students at risks and to take appropriate actions immediately.

However, this begins to change as more and more UK higher education institutions see the value of timely data for efficient decision making. For examples, online application has been widely implemented in higher education institutions in order for admissions team to respond to applicants timely. Real time or close to real time monitoring of student engagement will also be required to meet UK Border Agency (UKBA) and other legal requirements. With the increase usage of social media technologies, students are communicating and posting their feedback more and more via social media. Hence, immediate response and action can be taken to enhance student experience.

In terms of analytics, some of these higher education institutions have developed various analytical tools to gain insights for decision making. For examples, Open University has developed predictive modelling tools to predict student performance, in particular students who are at risk of failing a course. In developing the predictive models, it is found that a certain amount of trial and error is required for deciding which parameters are most informative for building the model. University of Bedfordshire built a customizable student engagement measurement index, which allows the users to pick and mix different engagement data types captured by the system. Plus, the users can use Analytic Hierarchy Process (AHP) to define their own weighting parameters that reflect the importance and priority of different engagement data types. Details of this project is presented in the next section.

Big data analytics involves making sense of large and complex datasets. Institutions must embark on various types of analytics, such as discovery, iteration, flexible capacity, mining and predicting and decision management [6]. Take the example of student engagement. The process of discovery involves exploring and connecting different engagement points of data, such as class attendance, VLE activities, digital library, university email etc. For emerging patterns to emerge, such as student retention risk factors, it is necessary to go through an iterative process, 
learn from each iteration and gradually move on to the next level of analytics, such as further data mining and predictive analytics in order to generate concrete insights on student engagement and retention. Big data analytics can also be processed automatically for specific decision to be taken. For example, academic staff will automatically receive an alert on disengaged students who are at risks of dropping-out.

System users need good data visualization to identify patterns easily in data analytics. In addition, the number of large datasets that can be presented can be limited by an online screen. Therefore, the form of data visualization must be appropriate and user-friendly so that users can digest and interpret the output of analytics effectively. Advanced data visualization includes dynamic data content, visual querying, multiple-dimension visualization, animated visualization, personalization and business-actionable alerts. Some advanced data visualizations have been developed in some of the projects of JISC's BI Programme. Open University, University of Bedfordshire, University of Manchester and University of Central Lancashire used dynamic bar and line graphs as digital management dashboard to present various aspects of key performance indicators (KPIs) and other strategic monitoring and planning information. University of Glasgow employed the Venn diagram to express the degree to which researchers' interests might match. University of East London used "dials" and "test tubes" to present data analytics on Student Lifecycle - Admissions Dashboard. And, University of Huddersfield had attempted to develop more advanced data visualization through user driven control of visualization in 3D form.

In terms of techniques in big data analytics, all BI projects were heavily reliant on the accessibility, quality and granularity of data they need in order to build appropriate techniques for BI models. For examples, University of East London realized that that the Higher Education Information Database for Institutions (HEIDI) data they need must be extracted and pre-processed into an appropriate format for their big data analytics. University of East London had to extract data from HEIDI and develop a range of Macros to reformat data that is appropriate for QlikView development and deployment. University of Glasgow improved their data access and comparison algorithms by the incorporation of stemming and fuzzy search, which allowed the system to suggest keywords from publications and project descriptions.

In summary, UK higher education institutions reported a number of key challenges in BI development and implementation. First of all, stakeholders play a major influence in the success of BI development and implementation. There were mismatched expectations among senior management team, BI vendors and providers, academic staff, and administrators, which could cause conflicts of interest and priorities in BI development and implementation. A clear governance structure must be put in place, followed by regular and continuous communication among key stakeholders for the success of change management. If external vendors would be involved in BI development and implementation, the selection criteria and process, as well as contractual agreement must be explicitly outlined to maintain good supplier relationship and maximize return on investment. It was found that the BI solution may also change the strategic direction due to challenges in data usage and technological limitations. Data accessibility, data ownership, data quality and timeliness are key challenging issues in BI development and implementation. Datasets, especially real time data and external data may not be accessible and usable. Hence, data cleaning and reformatting will be required to increase the quality and accuracy of the data. It is also important to conduct some feasibility testing as early as possible in the initial BI project. Technology could also be the bottleneck of the BI project success. The availability and capability 
of technological solutions would determine the extent of advancement in BI systems, such as intelligent tools and techniques for proactive and intelligent information processing, interactive and dynamic digital visualization. Lastly, the development and implementation process must be user-centered from the beginning to the end. This will motivate and encourage senior managers, academic staff and administrators to see the value and use the BI system for better management and strategic planning.

\section{A Case Study on The Use of Big Data Analytics on Student Engagement}

Kuh [7] and Trowler [8] believe that the success and development of higher education students has less to do what they contribute or where they study but what they do during the course of their study as student. Therefore, student engagement is viewed as an important antecedent to student learning and achievement, as well as to institutional success. Trowler [8] conducted a thorough literature review on student engagement for The Higher Education Academy and defined student engagement as, "Student engagement is concerned with the interaction between the time, effort and other relevant resources invested by both students and their institutions intended to optimize the student experience and enhance the learning outcomes and development of students and the performance, and reputation of the institution. (p.3)" Coates [9] argues that student engagement is useful for managers because by monitoring student engagement, institutions can identify areas of good practice as well as areas for improvement.

In 2009, University of Bedfordshire (UoB) began to see the value of big data analytics for managing student engagement. As a result, the University and a BI vendor had jointly developed a student engagement tracking system (SETS) in 2009. The system aimed to support users, ie. faculty managers, administrative and academic staff, to identify individual students' disengagement before it became significant. This would allow staff to take appropriate actions for students who were at risks due to poor engagement.

Although the system went live in December 2009, it served as an information source, rather than a big data analytic system. Most users highlighted that the system's interface was fairly basic and expressed desire for more enhanced functionalities. The University was aware that the system had great potential and would like to build on the system further. Through the funding of JISC's BI Programme, the University was looking into developing a BI solution or toolkit with enhanced functionalities for big data analytics. In particular, the users would like to be able to monitor and understand student engagement behavior at different levels (individual, group and cohort, etc) over different period of time.

The objectives of the project were to benchmark UoB's BI maturity level, identify the BI toolkit requirements specification and develop enhanced BI functionalities for student engagement analytics. A university wide BI survey was carried out with academic, administrative and management staff. Forty two validated questionnaires were received. Survey respondents covered key representatives of SETS users, including academic staff, field administrators, faculty managers, course leaders, researchers and senior managers. Respondents also provided their comments and suggestions via open questions in the survey. Due to a small sample of survey, the investigation was triangulated with other research methods, such as focus groups and interviews. One focus group discussion was carried out with academic staff to collect views and opinions on how to make better use of SETS, the potential applications of BI systems with SETS data and the 
anticipated challenges. Another focus group was held with senior management staff and key SETS users to discuss the benefits, limitations and future improvement of SETS. Six semi-structured interviews were also conducted with academic staff and faculty managers to discuss their experience and opinions on the use of SETS and their desired applications of big data analytics in the system.

First of all, BI maturity level at UoB was assessed based on the JISC infoNet BI Maturity conceptual framework. According to JISC, a maturity model is a good way of describing an area of project, so that practitioners can communicate with one another, describe progress in project, and identify shared goals and problems. There are six stages in the BI maturity model:

- Stage 1 - Data are fragmented and distrusted - scattered among traditional, often locally held data sources; manual reports are available to departmental, faculty and institutional management

- Stage 2-Information is increasingly coherent, held in centrally managed system(s) with clear local responsibility for data entry and data quality. Most reporting is still manual.

- Stage 3 - A Business Intelligence (BI) project is started, and a vendor and system are selected.

- Stage 4 - An initial BI System is put in place which allow managers at each level to access data when they need to.

- Stage 5 - The BI system and its links to data sources are increasingly automated; reporting becomes more sophisticated and spreads to a wider user population.

- Stage 6 - Systems are used for evidence-based decision-making and for predictions, models and assessment of future options.

Based on the evidence of our various investigations and assessments, it is evident that UoB had moved forward from BI maturity stage 1, 2 and 3 to stage 4, in which an initial BI system (SETS) was put in place allowing managers at each level to access data when they need to. However, the SETS project was still in its infancy in terms of realizing its full potential as a data source to provide evidence-based decisions and planning. The UoB senior management team had demonstrated their strong support and provided appropriate financial resources for the improvement of the existing SETS to leverage its value. The project would enable the University's BI maturity level move towards Stage 5 or 6 .

As a result, UoB worked jointly with an BI vendor and developed an improved SETS based on the BI toolkit requirements specification identified from the study. Big data in the form of student engagement are now automatically and efficiently collected and processed for reporting through a number of interactive dashboards. The dashboards present various types of data visualization to users and allow users to make more informed decisions related to student engagement analytic and management.

\subsection{Student Engagement Measurement Index}

Most users would like to have the flexibility for selecting engagement measurement criteria. Some comments were, "the ability to interrogate easily", "be able to rank the importance of the information", and "be able to prioritize the importance of different types of engagement". One faculty manager commented, "I'd like to select and define my criteria for checking student engagement". The improved system gives users the default engagement measuring index, as well as the flexibility to customize the index and reporting based on their respective analytic requirements as below: 
- Use default engagement measuring index - The index is based on the common perception and definition which constitutes student engagement.

- Customize the index system with their selected engagement types. Users are able to pick and mix different engagement data types captured by the system.

- Priorities the importance of different types of engagement, e.g. class attendance is more important than others.

The default engagement measurement index consists of the average scoring of student's engagement on predetermined events based on the impact and decay factors. The impact factor refers to the level of importance of each engagement event. The decay factor refers to the value that does not affect scoring after a certain period of time. The actual scoring is presented in percentage and with color indicators as depicted in Dashboard 1 and 2. The color indicator helps the users to identify students who are disengaged and at risks, ie. in red color.

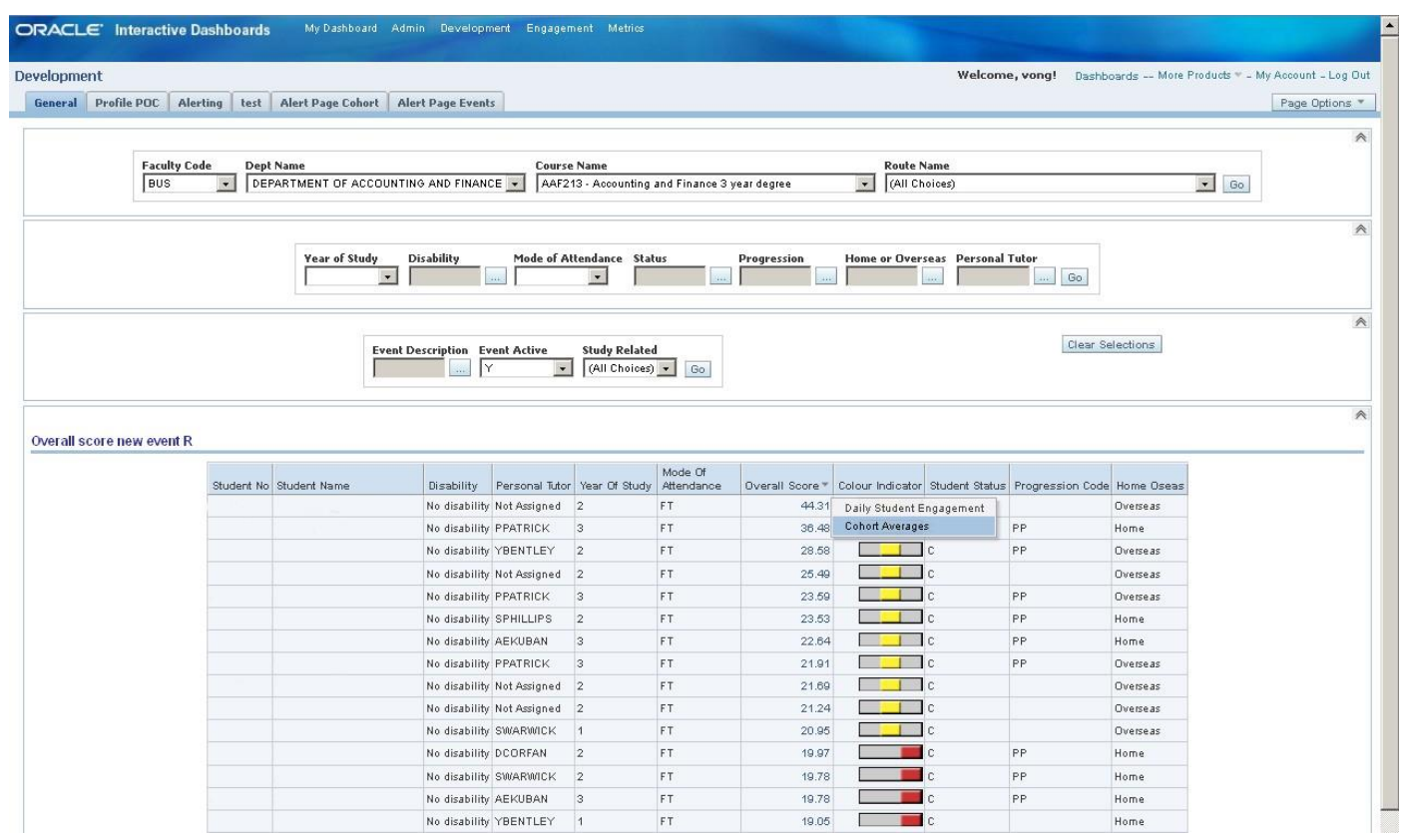

Dashboard 1: Student Engagement Measurement Reporting

\begin{tabular}{|l|c|c|c|c|c|c|c|c|c|c|c|c|c|c|c|}
\hline Student Ho: \\
Total Impact:
\end{tabular}

Dashboard 2: Student Engagement Scoring

Users can either use the default engagement measurement index or customize their enagement measurement index. Dashboard 3 shows the function for users to customize their own impact and decay factors based on their perceptions and definitions on student engagement weightings. The engagement weighting parameters vary between different 
engagement events and student cohorts because students are not expected to engage in all events at all time. For example, some degree courses expect their students to engage more in virtual learning platform than in-class attendance.

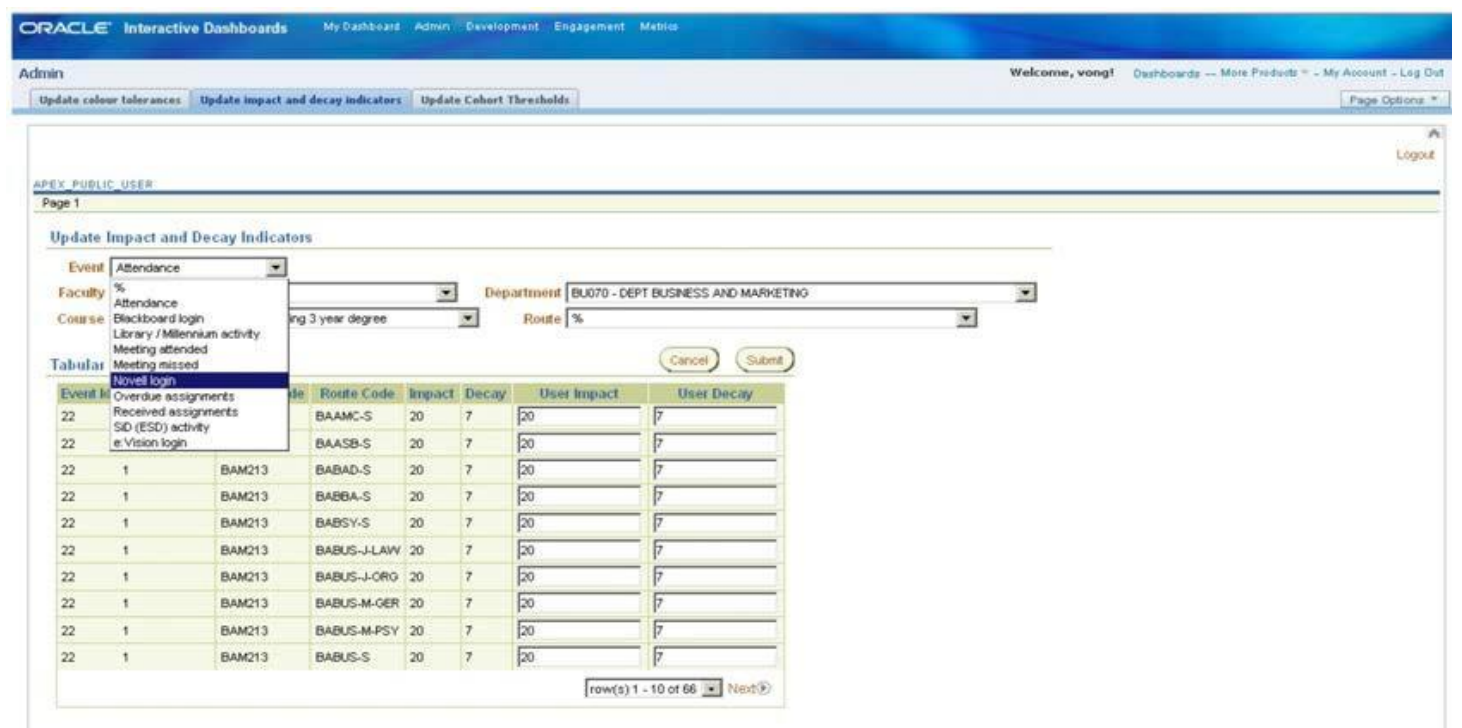

Dashboard 3: Student Engagement Measurement Modifier

\subsection{Interactive Dashboard for Reporting}

Users were expecting an interactive dashboard for retrieving outputs from the system. Some comments were, "Output to be useful, easy to read and understand", "the ability to generate exception report" and "useful report based on pre-determined criteria". One manager expressed, "I want quick, easy and user friendly and customizable report for starboards." One faculty manager commented, "The output should be interactive, allows me to generate reports for different purposes." The interactive dashboard in the improved system can provide the ability to create recurring standard report and ad hoc (demand) reports through various interactive visualizations (as depicted in Dashboard 4). These reports can be generated either by request of an end-user or refreshed periodically through an automatic scheduler (ie. weekly, fortnightly, monthly, quarterly). Users are also allowed to modify and save their report parameters, such as frequency, date ranges, course and/or unit cohort. Key functionalities of reporting include: (1) Standard View - Standard report that provides an overview of student engagement activities based on a set of default date ranges and pre-defined parameters related to student engagement activities. (2) Selective View (Pick n Mix) - User could select or modify parameters or engagement events in order to view different types of engagement data according to their priorities.
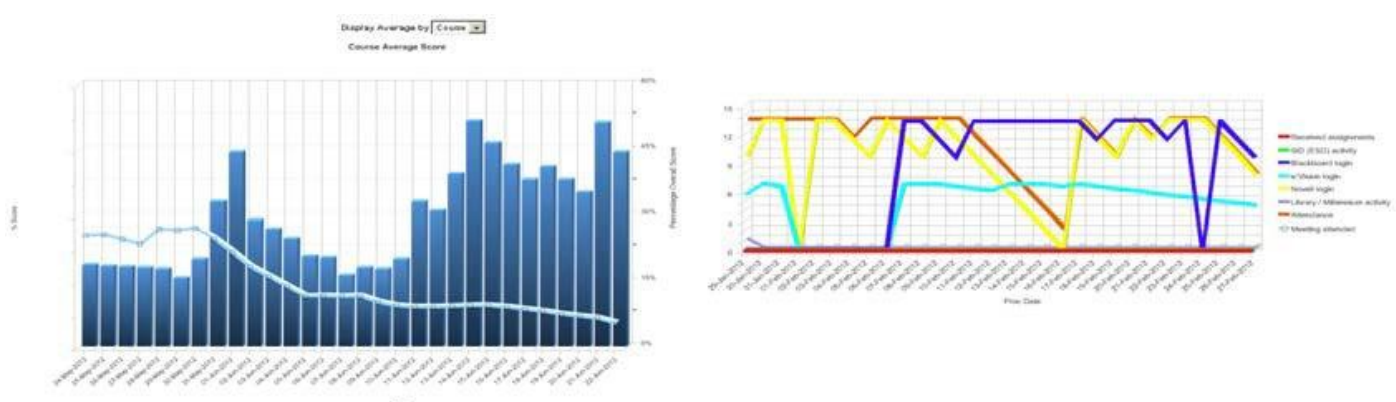

Dashboard 4: Interactive visualizations 


\subsection{Alert System}

Users found it useful to have some kind of alert functions in SETS for monitoring disengaged students who are at risk. For example, the system would automatically flag out individual students or groups at risk for early intervention. Some comments were, "automatic report of students at risk immediately they trigger a threshold of failure", "make it easier for staff to identify students at risk". One academic staff expected the system to detect disengaged students by commenting, "... to be able to pinpoint as early as possible an "at risk" student because early indicator of engagement can help support/retain students." The risk alert function provides the ability to alert users of exception activity of student engagement, for example, disengaged students who are at risk can be identified at the early stage. Users could be notified automatically through push mechanism, such as email, pop-up window. Further development is required for an automatic alert function as stated in the desired toolkit requirements.

This project has demonstrated the value for making informed and analytic-based decisions on student engagement activities. The improved SETS becomes an essential system for processing big data as well as reporting student engagement trends. The system could also benefit student retention, whereby disengaged students who are at risk of dropping out could receive support at early stage. The ability for users to customize their analytic requirements and engagement measures, coupled with various types of data visualizations, such as graphs and matrix bar charts have increased the number of usage in the University. This leads to senior management buy-in for more user licenses and for installing more engagement monitoring equipment across the University.

\section{Big Data Research Implications for Higher Education}

Clearly, big data analytics can provide unique and valuable insights into student admission trends, student engagement, student retention and progression issues, research investment and impact analysis, optimization in university's infrastructure and many other higher education related issues. Future big data research for higher education can focus on higher level of big data analytics maturity level as more and more institutions are valuing and starting to implement big data analytics. This may include research on advanced big data analytics techniques and models for evidence-based and data-driven decision-making. Statistical forecasting, complex querying, casual analysis, optimization, natural language processing and predictive modeling become increasingly important for good evidence-based and data-driven decision making.

As real time or close to real time data is becoming more valuable for higher education institutions, future research may look into the process and usage of real time or close to real time data in higher education. Future research may also take relevant external data into account, such as the Higher Education Information Database for Institutions (HEIDI) data, the Research Excellence Framework (REF) data, graduate employability data, National Student Survey (NSS) data and even students' social media data.

For big data analytics to be useful and usable for key stakeholders, advanced data visualization is an area to be investigated in terms of usability and interactivity for users, especially senior management in higher education. Due to the increasing amount of distributed data from different 
sources, researchers should also look into big data models and techniques in relation to social, economic and cognitive dimensions. Behavioral analytics is another area should be considered for research as individual and collective learning behavior and performance of students could be monitored and improved throughout the course of studies. Social network theories could also use big data to study the dynamics of formal and informal networks as they form and evolve, as well as to examine the impact on individual, network and organizational behaviors.

Organizational and transformational issues in big data analytics must be continuously studied as higher education institutions finding strategies to manage business and big data alignment, knowledge management, change management and business process transformation. This area of big data research may also have an impact on the organizational leadership and governance.

\section{Acknowledgement}

The author has participated in the JISC's BI Programme and would like to acknowledge and thank the financial and project management support from the Business Intelligence Programme, funded by JISC's Organizational Support committee and the University of Bedfordshire. The author would also like to thank all the JISC's BI project partners who shared valuable insights on business intelligence and analytics in UK Higher Education through JISC's BI Programme.

\section{References}

[1] H. Chen, R. Chiang, and V. Storey, "Business Intelligence and Analytics: From Big Data to Big Impact,” MIS Quarterly, vol. 36 (4), pp. 1165-1188, 2012.

[2] U. Kelly, I. McNicoll and J. White, "The Impact of Universities on the UK Economy", Universities UK (ISBN: 978-1-84036-304-3).

[3] J. Bichsel, "Analytics in Higher Education - Benefits, Barriers, Progress, and Recommendations," Research Report, EDUCAUSE Center for Applied Research, August 2012, available from http://www.educause.edu/ecar.

[4] P. B. Goes, "Big Data and IS Research," MIQ Quarterly, vol. 38, no. 3, September 2014, pp. iii-viii.

[5] Infokits on Business Intelligence, JISC infoNet, available from http://www.jiscinfonet.ac.uk/infokits/business-intelligence/

[6] "Big data analytics - Advanced analytics in Oracle database", an Oracle White Paper, March 2013.

[7] G. D. Kuh, "Assessing What Really Matters to Student Learning: Inside the National Survey of Student Engagement," Change, vol. 33, no. 3, 2001, pp. 10-17.

[8] V. Trowler, "Student Engagement Literature Review," The Higher Education Academy, York, 2010.

[9] H. Coates, "Development of the Australasian Survey of Student Engagement (AUSSE)," Higher Education, vol. 60, no. 1, 2010, pp 1-17. 